\title{
A IGREJA UNIVERSAL DO REINO DE DEUS E AS «RAABES MODERNAS» NO CONTEXTO PORTUGUÊS: UMA (DES)CONSTRUÇÃO DE VIOLÊNCIAS?
}

Monise Martinez ${ }^{1}$

Resumo: O presente artigo tem como objetivo promover uma reflexão acerca da proposta de assistência a mulheres que sofreram (e sofrem) violência doméstica e/ou familiar apresentada no âmbito do projeto Raabe, concebido pela Igreja Universal do Reino de Deus em sua atuação recente no contexto específico da sociedade portuguesa. Para tanto, será feita uma análise do discurso institucional de apresentação do projeto, publicado na página oficial da igreja em Portugal, a partir de dois eixos de discussão principais: o modelo de conduta feminina apresentado pela igreja como resolutivo às consequências geradas pela exposição de mulheres aos episódios de violência doméstica e/ou familiar, e a partir dele, a proposição de questionamentos, à luz das considerações de Pierre Bourdieu sobre a dominação masculina, acerca dos pressupostos que embasam o projeto e a consequente categorização das mulheres que pretendem auxiliar como vítimas, culpadas ou cúmplices.

Palavras-chave: Feminilidade. Violência Doméstica. Violência Simbólica. Igreja Universal do Reino de Deus; Projeto Raabe.

Resumen: El presente artículo tiene como objetivo proponer una reflexión sobre la propuesta de asistencia a las mujeres que sufrieron (o sufren) episodios de violencia doméstica y/o familiar presentada en el marco del proyecto Raabe, realizado por la Iglesia Universal del Reino de Dios en su actuación reciente en el contexto especifico de la sociedad portuguesa. Para hacerlo, se hará una análisis del discurso institucional para la presentación del proyecto, publicado en la sitio web oficial de la iglesia en Portugal, partiendo de dos ejes de discusión principales: el modelo de conducta femenina presentado por la iglesia como resolutivo a las consecuencias generadas por la exposición de mujeres a 
los episodios de violencia doméstica y/o familiar y, desde ello, la proposición de cuestionamientos, bajo las consideraciones de Pierre Bourdieu sobre la dominación masculina, sobre los presupuestos que fundamentan el proyecto y la consecuente comprensión de las mujeres que se proponen a ayudar como victimas, culpables o cómplices.

Palabras-clave: Femineidad. Violencia Doméstica. Violencia Simbólica. Iglesia Universal del Reino de Dios. Proyecto Raabe.

\section{INTRODUÇÃO}

Fundada em 1977 no Rio de Janeiro pelo bispo Edir Macedo, a Igreja Universal do Reino de Deus (IURD) é atualmente compreendida como uma denominação evangélica que, no âmbito dos estudos realizados sobre $\mathbf{0}$ pentecostalismo no contexto brasileiro, foi considerada como parte do que o sociólogo Paul Freston (1994) definiu como «terceira onda do pentecostalismo clássico»e, posteriormente, os sociólogos Ricardo Mariano (1994; 2004) e o antropólogo Emerson Giumbelli (2001)

2 Os costumes de santidade nesse contexto referido dizem respeito ao caráter do asceticismo
96

definiram como «neopentecostal»e «póspentecostalismo» - classificações que comumente contextualizam a IURD como parte de um movimento dissidente do pentecostalismo norte-americano clássico e que, entre outras coisas, caracterizou-se por pregar e propagar a Teologia da Prosperidade e por desapropriar-se dos tradicionais costumes de santidade $^{2}$ vinculados à imagem dos grupos religiosos pentecostais (cf. Mariano, 1996).

Tendo angariado um número de fiéis considerável durante os primeiros anos de sua atuação originária no contexto brasileiro, o processo de transnacionalização da IURD, que consistiu em sua instalação, alicerçada por pressupostos mercadológicos, em outros países (cf. Oro, 2004), teve início em meados da década de 1980, tendo avançado com mais ímpeto a um maior número de países nos anos 1990 (cf. Freston, 1999), década na qual expandiu-se consideravelmente pelo continente europeu ao adentrar estrategicamente por Portugal (cf. Aubrée, 2000), cuja facilidade do idioma e o perfil migratório de grande parte fiéis angariados facilitou a sua

- que remete a negação dos prazeres da carne típico das igrejas pentecostais (cf. Mariano, 1996). 
expansão pelo continente (cf. Aubrée, 2000) até alcançar presença nos 21 países europeus nos quais está instalada na atualidade (cf. Lorensini, 2015).

Apesar das singularidades que envolveram os processos de transnacionalização da IURD, bem como o desenvolvimento de novas estratégias para sua adaptação em contextos diferentes, a implementação da igreja em diferentes contextos nacionais europeus resultou de alguns procedimentos comuns às suas práticas para esses fins, como a realização de um levantamento prévio sobre características dos países e cidades de interesse, no qual privilegiava-se uma avaliação antecipada de suas possíveis contingências na angariação de fiéis e, como um fator de vantagem, a existência de uma presença significativa de brasileiros ou da população hispânica nos locais selecionados (cf. Oro, 2004), à parte de outros pormenores contextuais que, no caso de Portugal, consistiram num investimento prioritário numa população maioritária de mulheres com baixa escolaridade, pertencentes às camadas populares, domésticas e/ou

\footnotetext{
${ }^{3}$ A nomenclatura «Centros de Ajuda Espiritual» foi implementada no contexto português já nos anos 2000, como uma tentativa de dissociar a imagem a pretensão da Universal em ser
}

imigrantes (cf. Freston, 1999; Mafra, 2003).

Dentre as diferentes estratégias adotadas pela igreja para inserir-se no contexto português, o investimento nos meios de comunicação e a implementação de projetos e campanhas de assistência social fizeram parte do eixo das ações estratégicas principais adotadas pelo grupo para angariar fiéis (cf. Freston, 1999; Oro, 2004). No âmbito dessas iniciativas sabe-se, por exemplo, da existência de programas como o «Eu Sou da Paz», culto específico realizado nos Centros de Ajuda Espiritual $^{3}$, o «Coração de Ouro», através do qual se organiza a coleta de bens perecíveis e não perecíveis para distribuição entre famílias carenciadas inscritas no programa, o «Ler e Escrever», que tem como foco os investimentos na alfabetização dos frequentadores, para além dos programas de auxílio à família de usuários de drogas, a construção de um lar para idosos (cf. Rosas, 2016) e, mais recentemente, um programa de auxílio voltado às mulheres que sofrem e/ou já sofreram violência doméstica e familiar:

propriamente uma igreja, evitando o embate direto com a Igreja Católica preterido no momento de sua incursão no país. (cf. Swatoviski, 2010). 
o projeto Raabe - Rompendo o silêncio que, à parte do contexto português, integra os braços de ação da igreja atuantes em outros países, incluindo o Brasil.

Divulgado em Portugal como uma iniciativa que integra a rede Godllywood- projeto presente em 70 países na atualidade que apresenta como proposta central a valorização e o empoderamento das mulheres por meio da recuperação de uma essência feminina prescrita por Deus (cf. Teixeira, 2014) — , o projeto Raabe foi concebido por Cristiane Cardoso, filha primogênita do bispo fundador da igreja, e se propõe a oferecer ajuda psicológica e emocional às vítimas de violência doméstica através de uma proposta conciliadora, na qual os «lares destruídos pela violência» (cf. Projeto Raabe, s.d) possam ser descontaminados através da proposta de auxílio delineada em meio a uma consolidada prerrogativa evangelizadora, típica das ações assistencialistas desenvolvidas pela IURD (cf. Rosas, 2014).

Partindo desse contexto, o presente trabalho terá como objetivo promover uma reflexão acerca da proposta de assistência apresentada no âmbito desse projeto no contexto
98

português tomando como objeto de análise o discurso de apresentação institucional que o engendra, publicado na página oficial do projeto em Portugal (ver Anexo), a começar pela exposição e discussão do modelo de conduta feminina apresentado pela igreja como resolutivo às consequências geradas pela exposição de mulheres aos episódios de violência doméstica e/ou familiar.

\section{RAABE: UM MODELO DE MULHER A SER SEGUIDO}

Prostituta em Jericó, cidade estratégica localizada no reino de Canaã (Terra Prometida), a personagem bíblica Raabe é primeiramente referida na Bíblia em uma narrativa do Livro de Josué, Antigo Testamento. Nessa passagem, centrada no episódio do trajeto percorrido pelos hebreus, descendentes de Abraão, para alcançar o território prometido por Deus (cf. Gênese 12, 19), Raabe exerceu um importante papel para que a conquista do reino cananeu se concretizasse: abrigou dois forasteiros espias em sua casa e, em troca da proteção de sua família e morada, não permitiu que fossem encontrados pelo rei Jericó, contribuindo com a concretização do plano de invasão elaborado pelos 
filhos de Israel a mando de Deus (cf. Josué 2, 1-24), ordenados à conquista de Canaã em razão da perversidade das nações que habitavam esse território (cf. Deuteronômio 9, 1-6).

No Livro de Josué, o ato misericordioso de Raabe para com os forasteiros é apresentado como resultado de sua consciência acerca da imponência do Deus que os amparava, tendo ela referido o terror de seu povo perante os hebreus em razão do conhecimento que teve dos feitos impressionáveis cumpridos pelo Deus que os regia e, também, por ter demonstrado - ainda que pelo medo - o seu respeito perante esse mesmo Deus reconhecido na obra de seus servos:

9 "Eu sei que o Senhor vos entregou esta terra; o terror de vós apoderou-se de nós, e todos os habitantes da terra estão desanimados por vossa causa. 10 Ouvimos dizer que vosso Senhor secou as águas do mar Vermelho diante de vós, quando saístes do Egito, e como, além do Jordão, tratastes os dois reis dos amoreus, Seon e $\mathrm{Og}$, os quais votastes ao

4 «1. A fé é o fundamento da esperança, é uma certeza a respeito do que não se vê. 2 Foi ela que fez a glória dos nossos antepassados. 3 Pela fé reconhecemos que o mundo foi formado pela palavra de Deus e que as coisas visíveis se originaram do invisível. 31 Foi pela fé que Raab, a meretriz, não pereceu com aqueles que resistiram, por ter dado asilo aos espias.» (Hebreus 11, 1-3.31: 1535-1536).

5 «14 De que aproveitará, irmãos, a alguém dizer que tem fé, se não tiver obras? Acaso esta fé poderá interdito. 11 Quando ouvimos isso, nosso coração desfaleceu e ninguém mais tem coragem de vos resistir, porque o Senhor, vosso Deus, é o Senhor nas alturas dos céus e aqui embaixo na terra"». (Josué 2, 9-11: 254).

Contudo, mais do que um ato de subserviência, a proteção dada por Raabe aos espias hebreus faz com que ela seja referida no Novo Testamento como um exemplo de salvação pela fé (cf. Hebreus $11,31)^{4}$, uma vez que na esperança de salvar-se, a personagem acredita na promessa que é feita pelos espias que abriga e, como prova de sua crença, amarra um cordão de fio escarlate à janela de sua casa para lembrá-los de que ela e os seus familiares deveriam ser salvos durante a invasão; além disso, é também o ato faz com que Raabe seja também mencionada como exemplo de fé que produz boas obras (Tiago, 2, 25) $)^{5}$, uma vez que através de sua atitude contribui com o alcance da Terra Prometida por parte dos hebreus.

salvá-lo? 15 Se a um irmão ou a uma irmã faltarem roupas e o alimento cotidiano, 16 e algum de vos lhes disser: "Ide em paz, aquecei-vos e fartai-vos", mas não lhes der o necessário para o corpo, de que lhes aproveitará? 17 Assim também é a fé: se não tiver obras, é morta em si mesma. 24 Vedes como o homem é justificado pelas obras e não somente pela fé? 25 Do mesmo modo Raab, a meretriz, não foi ela justificada pelas obras, por ter recebido os mensageiros e os ter feito sair por outro caminho? (Tiago 2, 14-17.24-25: 1540). 
No entanto, no discurso institucional do projeto Raabe divulgado pela IURD no contexto português (ver Anexo), a misericórdia da personagem para com os forasteiros é, a partir do episódio narrado no Livro de Josué, apresentada como um ato de autovalorização concretizado de modo consciente pela personagem bíblica:

o nome [do projeto] foi inspirado na personagem bíblica Raabe, uma prostituta sem rumo, com medo do que o futuro lhe reservava. Ela sabia que sua cidade, Jericó, seria invadida pelos hebreus, o povo de Deus, e que não haveria escapatória. Quando se viu diante de espiões hebreus, ao invés de denunciá-los, usou de misericórdia e acolheu-os, escondendo-os. Uma pessoa que antes não se valorizava, discriminada, percebeu seu valor e passou a ter um papel importante na história da humanidade. (Projeto Raabe, s.d: linhas 13-18, destaque meu).

Essa perspectiva

da

autovalorização pode associar-se ainda a uma leitura da narrativa bíblica também relacionada ao desfecho compensatório atribuído a Raabe em razão de sua obra e

6 «1 Genealogia de Jesus Cristo, filho de Davi, filho de Abraão. 2 Abraão gerou Isaac: Isaac gerou Jacó. Jacó gerou Judá e seus irmãos. 3 Judá gerou, de Tamar, Farés e Zara. Farés gerou Esron. Esron gerou Arão. 4 Arão gerou Aminadab. Aminadab gerou Naason. Naason gerou Salmon. 5 Salmon gerou Booz, de raab.» (Mateus 1, 1-4: 1285).

${ }^{7}$ Reconhecida como um movimento doutrinário a partir da década de 1970, essa teologia foi substancialmente guarida por grupos fé, uma vez que após ser salva pelo povo de Josué, a personagem gentia ganha permissão para viver junto do povo de Israel e casa-se com Salmon, o príncipe de Judá, passando a integrar a genealogia de Jesus Cristo ${ }^{6}$ (cf. Mateus 1, 1-4) e apresentando uma trajetória de sucesso, destacada discurso institucional do projeto promovido pela IURD pela sua ascensão de mulher «discriminada» à «importante para a história da humanidade».

Prerrogativa fundamental para a teologia da prosperidade ${ }^{7}$ que, entre outras coisas, caracteriza substancialmente a vertente neopentecostal da qual a IURD faz parte (cf. Mariano, 1996), a valorização da narrativa de Raabe como um percurso de êxito centrado no esforço individual conforma-se a uma compreensão da fé como principal meio de obter a felicidade, que é garantida por Deus ao fiel de modo proporcional ao grau de espiritualidade do mesmo.

pentecostais (cf. Mariano, 1996), cujas origens remontam ao protestantismo (cf. Campos, 2005), tornando-se conhecida pela pregação subvertida do adágio franciscano «é dando que se recebe»e pela crença de que todo cristão está destinado a prosperar materialmente (cf. Mariano, 1996), razão pela qual eventualmente é designada como «Evangelho de Sucesso» (cf. Vilaça, 2005). 
Assim, no contexto dos preceitos que sustentam a teologia apresentada, a trajetória de Raabe - permeada por um argumento moral explicitado no texto bíblico - corresponde analogicamente ao percurso que deve ser cumprido pelas mulheres que pretendem frequentar o projeto que leva o seu nome, uma vez que, referidas no discurso institucional da igreja como «sobreviventes» (Projeto Raabe, s.d: linha 31) ou «Raabes modernas» (Projeto Raabe, s.d: linha 19), as vítimas de violência doméstica ou familiar são apresentadas como aquelas que «têm no grupo de apoio da Universal uma chance de romper o silêncio e lutar contra o medo, as frustrações, os traumas, e dar início a uma nova vida» (Projeto Raabe, s.d: linhas 19-21), isto é, aquelas que tal como Raabe têm a possibilidade de se regenerar e trilhar um caminho de sucesso através da busca por «perceber o seu valor» (cf. Projeto Raabe, s.d: linha 24).

Nesse sentindo, apresentando uma proposta de intervenção centrada no investimento da mulher em si própria (cf. Projeto Raabe, s.d: linha 25) a partir da questionável - apesar de teologicamente contextualizada interpretação de Raabe como uma mulher plenamente consciente do seu
101

processo de escolha pela autovalorização, a analogia tecida entre a personagem bíblica e as vítimas a que o projeto Raabe se propõe a prestar auxílio nos faz questionar em que consiste o ato de valorizar-se ou não no discurso promovido no âmbito do projeto e, afinal, a sua eficácia enquanto resolução para uma situação de violência doméstica e/ou familiar — reflexão na qual está centrado o tópico seguinte do presente artigo.

\section{NOÇÕES DE VALOR E DESVALOR NO CONTEXTO IURDIANO}

No âmbito do discurso institucional iurdiano referente ao projeto Raabe, o ato de autovalorização das mulheres que são vítimas do crime de violência doméstica e/ou familiar é apresentado como um «reencontro» das mesmas com o «respeito próprio» (cf. Projeto Raabe, s.d: 24). Assim, sendo elas «Raabes modernas» que devem agir de modo analógico à Raabe bíblica, parte-se do princípio de que a valorização a ser alcançada por elas associa-se a um percurso de escolha consciente gerido por atos que se deem em razão do temor a Deus (cf. supra: 4) e da fé (cf. supra: 5), 
perpassando pela renúncia de uma vida infame para o alcance da realização plena que, no contexto bíblico, dá-se através do casamento, que se opõe à vida infame, e da procriação, que insere Raabe na linhagem de Cristo.

A compreensão da honra e da infâmia vinculadas à mulher no contexto iurdiano está associada, por sua vez, a uma proposta de conduta feminina articulada pela criadora do projeto Raabe no âmbito de outras ações ensejadas pela igreja também encabeçadas por ela: o ideário de mulher virtuosa, delineado em conformidade com uma projeção feminina descrita no capítulo 31 do Livro Provérbios, cujo primeiro versículo refere prontamente a associação entre virtude e valor: «Uma mulher virtuosa, quem pode encontrá-la? Superior ao das pérolas é o seu valor» (Provérbios 31, 10: $815)^{8}$.

A proposta de caráter formativo e disciplinar concebida por Cristiane Cardoso às mulheres é amplamente referida em um livro de sua autoria intitulado Mulher $V$ : moderna à moda antiga (2013), no qual cada um dos capítulos apresenta características e/ou

\footnotetext{
${ }^{8}$ No livro A Mulher V, de Cristiane Cardoso, a tradução do versículo apresentado corresponde à: «Mulher virtuosa, quem a achará? O seu valor
}

comportamentos que devem ser buscados pela mulher que se pretende virtuosa e também os que devem ser rechaçados, como a negação do alcance de uma sabedoria ímpar segundo a qual deverá aceitar as repreensões consideradas necessárias para a sua aprendizagem, além de temer a Deus (cf. Cardoso, 2013), sendo descrita pela autora como uma «cabeça de vento» (cf. Cardoso, 2013: 19) se optar por não fazer essa escolha.

Partindo desse contexto, é possível compreendermos que os pressupostos que gerem a busca por tornar-se uma mulher virtuosa assemelham-se, em partes, a proposta de transformação da vítima de violência doméstica e/ou familiar em uma mulher honrada no âmbito do projeto Raabe. Assim, tal como no percurso de sucesso em prol da virtuosidade, a vítima que se dispõe a reencontrar o seu valor deverá superar as adversidades proporcionadas pelas situações incólumes de violência pelas quais passou (ou passa) partindo inicialmente da consciência de que é «feminina, [e de] que deve se cuidar [e] aprimorar sua autoestima» (Projeto Raabe, s.d: linha 25), o que pressupõe que

muito excede o de finais joias» (cf. Cardoso, 2013: 16). 
a recuperação da vítima provirá da sua adequação a um ideário de feminilidade ensejado pela igreja. Mas afinal, em que consiste esse ideário e de que modo pode apresentar-se como solução ou problema no contexto propositivo do projeto?

\subsection{A Feminilidade Raabeana: Uma Nova}

Violência?

Em língua portuguesa, o termo feminilidade engloba simultaneamente os sentidos atribuídos ao termo «feminino» nesse contexto linguístico. Assim, ao passo que é empregado para designar os padrões sexuais e sociais tradicionalmente identificados como qualidades ou caráter da mulher, é também empregado para designar a sua descoberta da subjetividade (cf. Macedo e Amaral, 2005) que, na visão de Beauvoir (2009), tal como os padrões referidos, constrói-se em meio a um paradigma de sociedade patriarcal.

A constituição epistemológica dessa forma de organização social remonta, por sua vez, a uma noção de diferença sexual delineada pela nova ordem cívica proposta por Platão e Aristóteles no século IV a. C. - uma compreensão da sociedade pautada na subordinação e dominação daqueles que, num sistema de diferenciação hierárquica entre os seres, fossem considerados não-homens e não-gregos (cf. Ramalho, 2013). Esse sistema de diferenciação é também aquele que embasa, em partes, a análise da dominação masculina enquanto uma ordem social apresentada por Bourdieu (1998).

Para o sociólogo francês, numa sociedade constituída a partir da compreensão das diferenças sexuais como um conjunto de oposições homólogas, os atributos e atos sexuais são diretamente influenciados por uma antropologia e cosmologia androcêntrica que rege a divisão das atividades e das coisas, de modo que o patriarcado corresponde a um modelo de organização social que resulta $d a \mathrm{e}$ reafirma $a$ dominação masculina, sendo esta uma posição epistemológica e ideológica delineada a partir de uma compreensão hierárquica e assimétrica das diferenças sexuais nas quais ao sujeito social masculino é designada a posição de dominador e ao sujeito social feminino é designada a posição de subordinado, culminando na existência de uma dominação simbólica que, através de diferentes manifestações, modela a ordem social (cf. Bourdieu, 1998). 
No que tange as produções discursivas ambientadas na teologia, Elisabeth S. Fiorenza sublinha a existência de uma ideologia religiosa engendrada em conformidade com os preceitos de uma dominação masculina estrutural. No âmbito das religiões cristãs, essa ideologia permeia a organização de um cânone opressor, no qual as interpretações dos textos religiosos conservam as assimetrias que sustentam - e são sustentadas - pelo patriarcado (cf. Toldy, 2010).

A título de exemplo, refiro os trabalhos interpretativos ambientados em uma «teologia da mulher», marcados pelo ímpeto em compreender as «especificidades do feminino»a partir da natureza humana criada por Deus, leituras que visam não só afirmar a igualdade do homem e da mulher perante Ele como, ao mesmo tempo, sublinhar as suas diferenças justificando-as através das «disposições naturais» de ambos (cf. Toldy, 2009), prerrogativa essa que integra o proposta de autovalorização da mulher no âmbito do projeto Raabe:

o projeto Raabe estende sua força a lares que também passaram a violência doméstica e hoje contam, como sobreviventes, como superaram, a maneira de não se igualar aos homens, mas sim somar com eles as suas diferenças, porém nunca serem desiguais. (Projeto Raabe, s.d).

Sem pretender-se, portanto, subversivo, o ideário de feminilidade que circunda os discursos disciplinares regidos pela IURD é ainda determinado com maior afinco pela autora através da concepção que apresenta do casamento que, contraditoriamente, ao passo que deve ser compreendido como uma situação problema para grande parte das mulheres atendidas pelo projeto, é fortemente delineado pela autora como um espaço a ser tomado como positivo por elas, que cumprirão a sua trajetória de sucesso zelando pelo próprio casamento, ainda que este possa ser a causa da situação de violência vivenciada pela mulher (Projeto Raabe, s.d: linhas 24-28).

À parte desta contrariedade, é ainda de se sublinhar que a compreensão do matrimônio por parte de Cristiane Cardoso alinha-se às prerrogativas detalhadamente apresentadas em produções de sua autoria, como Mulher $V$ : moderna à moda antiga (2013) ou Casamento Blindado (2012), escrita em parceria com o seu marido, bispo da igreja. Nessas obras, os papéis e comportamentos que devem ser executados pelas mulheres são 
justificados por características que, de acordo com a vontade de Deus, lhes são constantemente apresentadas como inerentes, adequando-se a um ideal de feminilidade incapaz de romper com a estrutura patriarcal e fortemente arraigado na ideologia da domesticidade, como vemos no trecho a seguir:

[...] a mulher, por ficar em casa em companhia dos filhos e vizinhas, desenvolveu melhor a habilidade de comunicação verbal. Como a organizadora e enfermeira da família, se tornou expert em perceber detalhes e expressões faciais, sempre atenta ao estado físico e emocional das pessoas. Ela se tornou a arquiteta dos relacionamentos, a cola da família e da comunidade. (Cardoso e Cardoso, 2012: 139).

Ideologia cujas origens remontam à ascensão da burguesia industrial no século XIX, a domesticidade feminina tornou exponencial as propostas culturais delineadas ainda no Humanismo, ancoradas num modelo de educação feminina segundo o qual as mulheres deveriam ser preparadas para desempenhar com sucesso o papel de esposa e mãe (cf. Macedo e Amaral, 2005), papéis que são tomados como pontos-chave para a concretização da trajetória de sucesso da personagem bíblica Raabe e implicitamente para as mulheres que procuram o projeto de apoio à vítima de violência doméstica e/ou familiar desenvolvido pela igreja, haja vista o fato do discurso institucional do projeto buscar atenuar a situação de violência, apresentando-a como um problema a ser potencialmente resolvido entre marido e mulher (cf. Projeto Raabe, s.d: linhas 24-27).

Para além da questão da domesticidade, o ideal de feminilidade iurdiano proposto às mulheres ainda designa a elas um lugar subalterno no âmbito da vida conjugal, em que a submissão é apresentada como prerrogativa para o bom funcionamento da relação e como um instrumento que denota o poder designado às mulheres por Deus:

na Bíblia, a palavra [submissão] está relacionada a humildade, brandura, cumplicidade, confiança na liderança, maleabilidade, docilidade e respeito. É o contrário de desafiadora, rebelde, inflexível e resistente. Quer dizer que a mulher precisa de certas qualidades para trabalhar em parceria com o marido, a quem deve respeitar como líder. [...] Somos tão fortes que Deus nos orientou a "permitir" que nossos maridos nos liderem. Sim, permitir, porque senão acabamos mandando mesmo... Mas Deus quer que usemos nossa força de maneira diferente, mais sábia. (Cardoso e Cardoso, 2012: 157). 
Sendo a domesticidade e a submissão elementos que integram a compreensão do casamento aos moldes iurdianos, as relações conjugais e familiares não são tomadas como estruturas a serem questionadas, mas sim como vínculos a serem mantidos e/ou recuperados, de modo que no âmbito do projeto Raabe, à medida que a superação for alcançada pela mulher através de sua autovalorização, em conformidade com o padrão de feminilidade iurdiano, a situação de violência, apresentada como uma «guerra doméstica» (cf. Projeto Raabe, s.d: linha 28), supostamente deixará de existir.

Contudo, permeada por uma ideologia de dominação masculina que perpassa pelas interpretações do cânone religioso das quais se vale para construir e justificar as suas propostas e, consequentemente, pelas implicações dessa leitura no delineamento dos papéis e funções desempenhados pelas mulheres na vida conjugal e em sociedade, o discurso institucional através do qual o projeto Raabe é apresentado ao público oferece como auxílio às vítimas de violência doméstica e familiar uma proposta que, nos termos de Bourdieu (1998), pode constituir-se, afinal, como um ato de violência simbólica.

Descrita pelo autor como um tipo de violência instituída por meio da adesão do sujeito dominado que, na circunstância da dominação masculina, não tem hipótese de não ceder ao dominador em razão da naturalização das relações hierárquicas apresentadas como norma (cf. Bourdieu, 1998), a proposta de autovalorizar-se através da recuperação de uma essência feminina imutável e conformada uma ideologia da domesticidade e do patriarcalismo configura-se como uma violência simbólica à medida que se constitui em meio a naturalização das relações assimétricas entre homens e mulheres e vale-se de verdades religiosas supostamente incontestáveis para respaldá-las, convertendo-se contraditoriamente numa ação de violência que pretende auxiliar na superação de um trauma gerado por uma outra situação de violência.

\section{VÍTIMAS, CÚMPLICES OU CULPADAS CONSEQUENTES}

A considerar o modo como são apresentadas as mulheres no discurso institucional do projeto Raabe, percebe- 
se que há um esforço inicial em apresentá-las como como vítimas ao referi-las, por exemplo, como «Sobreviventes» (Projeto Raabe, s.d: linha 31). Nesse contexto, as referências que pretendem apresentá-las desse modo podem ser compreendidas a partir de duas perspectivas: uma mais discreta, em que através da identificação de seus agressores como «parceiros» (Projeto Raabe, s.d: linha 23) as mulheres são apresentadas como vítimas de seus cônjuges; e outra na qual a partir da analogia com a personagem Raabe as mulheres acolhidas pelo programa são apresentadas como vítimas das situações resultantes dos episódios de violência por ela vivenciados (Projeto Raabe, s.d: linhas 19-21).

Enquanto vítimas, as soluções apresentadas para a superação dos traumas são apresentadas, no entanto, como uma escolha consciente a ser feita pelas mesmas mulheres no caminho da autovalorização que, conforme já mencionado, é delineado em conformidade com o modelo de feminilidade apresentado pela igreja. Nesse sentido, responsáveis pela escolha de se manterem infames ou, através da solução proposta, tornarem-se honradas, as mulheres que integram o programa podem também ser compreendidas como vítimas de si mesmas, uma vez que o seu suposto ato de escolha pela trajetória raabeana culminará na compreensão de seu agressor como um parceiro beneficiado.

Nesse contexto, é ainda de se sublinhar ainda que, do ponto de vista da ideologia de dominação masculina, a atribuição dessa responsabilidade de escolha à mulher em situação de violência doméstica e/ou familiar pode ser compreendida, do modo como é organizada no discurso analisado, como uma estratégia de mantenimento do status quo. Nesse contexto, a cadência de naturalizações que favorecem o dominador podem ser entendidas como formas de manter o sujeito dominado em posição subalterna, como notamos, por exemplo, na conversão da submissão e da obediência feminina em elementos necessários para o alcance de uma honradez raabeana que, através da domesticação da mulher, não só atenua a própria substância que envolve uma situação de violência doméstica, apresentada como responsabilidade de ambos os cônjuges ao ser referida como «guerra doméstica» (Projeto Raabe, s.d: linha 28), como também atenua a ação do cônjuge, que passa de agressor a 
«parceiro errante», eventual vítima das circunstâncias.

Dessa perspectiva, a vitimização de si própria engendrada pela atribuição da responsabilidade pode, ainda, fazer com que ainda as mulheres sejam compreendidas como cúmplices, à medida que ao aceitarem os preceitos da honradez reproduzem contra si próprias a estrutura de dominação socialmente vigente, e como duplamente culpadas, no sentido de que ao rejeitar as condições do suposto poder de escolha que lhes é atribuído, tornam-se responsáveis pela sua escolha em manter-se infame, negando a própria ascensão pela honra, de modo que, tendo-se em conta as perspectivas interpretativas apresentadas, tornar-se-á vítima, culpada e/ou cúmplice pela situação na qual se encontra e que supostamente deveria ser combatida pelo projeto.

\section{CONSIDERAÇÕES FINAIS}

Tomando como um «à parte» as críticas contundentes que perpassam debates importantes sobre a compreensão da violência contra a mulher a partir da ideologia de dominação masculina neste artigo - como a questão a impossibilidade de ação do sujeito
108

dominado e da fixidez de sua condição de vítima -, a reflexão desenvolvida ao longo dos tópicos desse trabalho, embasada pela concepção de dominação masculina de Pierre Bourdieu, faz-nos pensar que, afinal, o discurso institucional do projeto Raabe analisado adequa-se, afinal, ao contexto social e discursivo que determina a sua produção tal como é feita, haja vista que se buscássemos compreendê-lo a partir de uma perspectiva relativa, na qual a relação de opressão não fosse tomada como parte inerente à sua própria constituição, a neutralização das interpretações discursivas apresentadas se conformariam ao discurso da igreja que, afinal, fazem das Raabes as suas Raabes modernas.

\section{REFERÊNCIAS BIBLIOGRÁFICAS}

Aubrée, Marion (2000), "La diffusion du pentecôtisme brésilien en France et en Europe: le cas de l'I.U.R.D”, in Lerat, Christian e Rigal-cellard, B. (orgs.). Les mutations transatlantiques des religions. Bordeaux: PUB, 149-157.

Beauvoir, Simone (2009), O Segundo Sexo. Rio de Janeiro: Nova Fronteira. 
Bíblia Sagrada, A.T e N.T. Português.

Tradução do Centro Bíblico Católico. São

Paulo: Edições Ave Maria.

Bourdieu, Pierre (1998), A dominação masculina. Rio de Janeiro: Editora Bertrand Brasil.

Campos, Leonildo Silveira (2005), “As origens norte-americanas do pentecostalismo brasileiro: observações sobre uma relação ainda pouco avaliada", Revista USP, São Paulo, 67, 100-115. Versão eletrônica, consultada a 03.03.2017, em:

http://www.revistas.usp.br/revusp/article

/view/13458.

Cardoso, Cristiane (2013). A Mulher V:

Moderna, à moda antiga. Rio de Janeiro:

Thomas Nelson Brasil.

Cardoso, Cristiane; Cardoso, Renato (2012), Casamento Blindado: o seu casamento à prova de divórcio. Rio de Janeiro: Thomas Nelson Brasil.

Freston, Paul (1999), “A Igreja Universal do Reino de Deus na Europa", Lusotopie, 383-403. Versão eletrônica, consultada a 03.03.2017, em: http://lusotopie.sciencespobordeaux.fr/fr eston2.pdf.

Giumbelli, Emerson (2001), “A vontade do saber: terminologias e classificações sobre o protestantismo brasileiro. Religião e Sociedade”, Rio de Janeiro, 21(1), 87-120. Versão eletrônica, consultada a 03.03.2017, em: http://docplayer.com.br/9201342-Avontadedo-saber-terminologias.html Igreja Universal do Reino de Deus (s.d), "Projeto Raabe/Quem somos", consultado a 03.03.17, em: http://projetoraabe.pt/quem-somos/.

Lorensini, Marco Antonio (2014), “Transnacionalização da Religião: A Presença da Igreja Universal do Reino de Deus no Brasil e no Mundo", in XXVII SIC - Salão de Iniciação Científica (Pôster). Consultado a 03.03.17, em: http://www.lume.ufrgs.br/bitstream/hand le/10183/136349/Poster_41194.pdf?sequ ence $=2$.

Macedo, Ana Gabriela; Amaral, Ana Luísa (orgs.) (2005), Dicionário da Crítica Feminista. Porto: Edições Afrontamento. 
Mafra, Clara (2003), “A Igreja Universal em Portugal", in Oro, Ari Pedro et al (orgs.), Igreja Universal do Reino de Deus: os novos conquistadores da Fé. São Paulo, Paulinas, 165-176.

Mariano, Ricardo (1996), “Os neopentecostais e a teologia da prosperidade," Novos Estudos CEBRAP, 44, 24-44. Versão eletrônica, consultada a 03.03.2017, em: http://novosestudos.org.br/v1/files/uploa ds/contents/78/20080626_os_neopentec ostais.pdf.

$$
\text { (2004), 'Expansão }
$$

pentecostal no Brasil: o caso da Igreja Universal", Estudos avançados, São Paulo, 18(52), 121-138. Versão eletrônica, consultada a 03.03.2017, em: http://www.scielo.br/scielo.php?script=s ci_arttext\&pid=S0103-

40142004000300010.

Oro, Ari Pedro (2004), “A presença religiosa brasileira no exterior: o caso da Igreja Universal do Reino de Deus", Estudos Avançados, 18(52), 139-155. Versão eletrônica, consultada a 03.03.2017, em: http://www.scielo.br/scielo.php?script=s
ci_arttext\&pid=S0103$\underline{40142004000300011}$

Ramalho, Maria Irene (2013), "Difference and Hierarchy Revisted by Feminism”, Anglo Saxonica , III (2).

Rosas, Nina (2016), “A Igreja Universal do Reino de Deus: ação social alémfronteiras", Ciências Sociais Unisinos, São Leopoldo, 52, (1), 17-26. Versão eletrônica, consultada a 03.03.2017, em: http://revistas.unisinos.br/index.php/cie ncias_sociais/article/view/csu.2016.52.1 .03 . (2014), As obras sociais da Igreja Universal: uma análise sociológica. Belo Horizonte: Fino Traço Editora.

Swatoviski, Claudia W (2010), “A Igreja Universal em Portugal: tentativas de superação de um estigma", Intratextos, Rio de Janeiro, Número Especial 1, 169192. Versão eletrônica, consultada a 03.03.2017, em: http://www.epublicacoes.uerj.br/index.php/intratexto s/article/view/416a.

Teixeira, Jacqueline (2014), "Mídia e performances de gênero na Igreja Universal: o desafio Godllywood", Religião e Sociedade, Rio de Janeiro, 
34(2), 232-256. Versão eletrônica,

consultada a 03.03.2017, em:

http://www.scielo.br/pdf/rs/v34n2/0100-

8587-rs-34-02-0232.pdf.

Toldy, Teresa (2009), "Notas para uma hermenêutica feminista da tradição cristã", Revista Portuguesa de História, 40, 197-211. Versão eletrônica, consultada a 03.03.2017, em: https://digitalisdsp.uc.pt/bitstream/10316.2/11969/3/08 $\underline{\% 20-}$ \%20Teresa\%20Martinho\%20Toldy.pdf ? $\ln =$ pt-pt. (2010), “A violência e o poder da(s) palavra(s): A religião cristã e as mulheres", Revista Crítica de Ciências Sociais, 89, 171-183. Versão eletrônica, consultada a 03.03.2017, em: https://rccs.revues.org/3761.

Vilaça. (2005). A religião e a Bíblia num quadro de liberdade religiosa, Revista Lusófona de Ciências da Religiões, Ano IV(7-8), 109-117. Versão eletrônica, consultada a 03.03.2017, em: http://revistas.ulusofona.pt/index.php/cie nciareligioes/article/view/4142/2836. 


\section{Anexo}

Muitos defendem que uma mulher agredida deve denunciar o autor da agressão. A maioria, infelizmente, não o faz, geralmente por medo de represálias.

Entretanto, só denunciar não basta. Há todo um processo psicológico, físico e até jurídico depois. E mesmo antes de uma mulher ir a uma delegacia denunciar alguém por maus tratos, há que se pensar.

É aí que entra o projeto Raabe, iniciativa da Universal criada pela escritora e apresentadora Cristiane Cardoso. Antes da denúncia, de fazer o Boletim de Ocorrência (B.O.), as voluntárias do Raabe conversam com a vítima, orientando-as emocionalmente. Depois, há todo um acompanhamento por parte de advogadas, psicólogas e médicas, não deixando a mulher sem apoio nessa traumática hora e bem depois dela.

O nome foi inspirado na personagem bíblica Raabe, uma prostituta sem rumo, com medo do que o futuro lhe reservava. Ela sabia que sua cidade, Jericó, seria invadida pelos hebreus, o povo de Deus, e que não haveria escapatória. Quando se viu diante de espiões hebreus, ao invés de denunciá-los, usou de misericórdia e acolheu-os, escondendo-os. Uma pessoa que antes não se valorizava, discriminada, percebeu seu valor e passou a ter um papel importante na história da humanidade.

Assim como a Raabe bíblica, as Raabes modernas têm no grupo de apoio da Universal uma chance de romper o silêncio e lutar contra o medo, as frustrações, os traumas, e dar início a uma nova vida. A violência doméstica e familiar não mais é o fim. Abusos físicos e psicológicos sofridos na infância, adolescência ou no relacionamento, por seus parceiros, são graves, mas perdem força quando a mulher percebe seu valor. No Raabe, a mulher reencontra algo chamado respeito próprio. Percebe que é feminina, que deve se cuidar, aprimorar sua autoestima — percebe que é, enfim, mulher, sem as competições entre os sexos que, na verdade, desvalorizam ambos os lados dentro e fora do lar. Homem e mulher se descobrem parceiros, e não adversários numa guerra doméstica.

Todos os meses, reuniões do projeto Raabe são realizadas nos templos da Universal — e em outros lugares — de vários países, acolhendo novas Raabes que recebem, inclusive, 
o apoio de outras sobreviventes, como são chamadas as mulheres que fazem parte do grupo. O projeto Raabe é aberto a qualquer mulher que sofra violência ou intimidação doméstica ou familiar. 